Research Article

\title{
Speciation Analysis of Arsenic Compounds by High-Performance Liquid Chromatography in Combination with Inductively Coupled Plasma Dynamic Reaction Cell Quadrupole Mass Spectrometry: Application for Vietnamese Rice Samples
}

\author{
Hai Anh Vu (D), Manh Ha Nguyen (D), Hong-An Vu-Thi, ${ }^{1}$ Quan Do-Hong, \\ Xuan Hoang Dang, ${ }^{3}$ Thi Ngoc Bich Nguyen, ${ }^{3}$ Hong Quan Trinh, ${ }^{3}$ Thuy Ly Bich, ${ }^{4}$ \\ Tien-Thanh Nguyen, ${ }^{5}$ Dung Le-Van, ${ }^{6}$ Minh Binh Tu, ${ }^{1}$ and Dinh Binh Chu $\mathbb{D}^{2}$ \\ ${ }^{1}$ Faculty of Chemistry, VNU University of Science, Vietnam National University Hanoi, 19 Le Thanh Tong, Hoan Kiem, \\ Hanoi 100000, Vietnam \\ ${ }^{2}$ Department of Analytical Chemistry, School of Chemical Engineering, Hanoi University of Science and Technology, \\ 1 Dai Co Viet, Hai Ba Trung, Hanoi 100000, Vietnam \\ ${ }^{3}$ Institute of Chemistry, Vietnam Academy of Science and Technology (VAST), 18 Hoang Quoc Viet, Cau Giay, \\ Hanoi 100000, Vietnam \\ ${ }^{4}$ School of Environmental Science and Technology, Hanoi University of Science and Technology, 1 Dai Co Viet, Hai Ba Trung, \\ Hanoi 100000, Vietnam \\ ${ }^{5}$ School of Biotechnology and Food Technology, Hanoi University of Science and Technology, 1 Dai Co Viet, Hai Ba Trung, \\ Hanoi 100000, Vietnam \\ ${ }^{6}$ Department of Chemistry, Vietnam Military Medical University, 160 Phung Hung, Ha Dong, Hanoi 100000, Vietnam
}

Correspondence should be addressed to Dinh Binh Chu; binh.chudinh@hust.edu.vn

Received 25 January 2019; Revised 8 April 2019; Accepted 16 April 2019; Published 28 April 2019

Academic Editor: Bengi Uslu

Copyright (c) 2019 Hai Anh Vu et al. This is an open access article distributed under the Creative Commons Attribution License, which permits unrestricted use, distribution, and reproduction in any medium, provided the original work is properly cited.

In this work, high-performance liquid chromatography in combination with inductively coupled plasma dynamic reaction cell quadrupole mass spectrometry was introduced and optimized for speciation analysis of five major arsenic species including arsenobetain (AsB), arsenite (As(III)), monomethylarsonic (MMA), dimethylarsenonic acid (DMA), and arsenate (As(V)) in rice samples. Five arsenic compounds were separated on a Hamilton PRP X100 strong anion-exchange column employed with the mobile phase that is compatible with mass spectrometry, containing ammonium carbonate, methanol, and disodium ethylenediaminetetraacetic acid. Arsenic compounds were detected online by inductively coupled plasma dynamic reaction cell quadrupole mass spectrometry utilizing oxygen as the reaction gas at a flow rate of $0.7 \mathrm{~mL} \cdot \mathrm{min}^{-1}$. Five selected arsenic species were baseline separated at the optimum experimental conditions. The excellent LOD and LOQ values of the developed method were achieved in the range of 0.5 to $2.9 \mu \mathrm{g} \cdot \mathrm{kg}^{-1}$ and 1.7 to $9.6 \mu \mathrm{g} \cdot \mathrm{kg}^{-1}$ for all species of arsenic, respectively. The ionization effect in plasma during chromatographic gradient elution was systematically investigated by using postcolumn injector. Arsenic compounds in rice samples were extracted by diluted nitric acid at elevated temperature. The extraction efficiency and the interconversion of target compounds during sample preparation were also assessed. The full validation of the developed method was performed by using certified reference material, BRC 211, from European Institute of Reference and Standard for speciation analysis. The recovery of all selected arsenic species was in the range of 70 to $135.5 \%$. The validated method was also applied to analyze rice samples collected from some contaminated rice fields. The results showed that As(III), DMA, and As(V) were found in all rice samples. Average concentration (range) of inorganic arsenic and DMA in all rice samples were 130.3 (65.5-228.1) and 32 (8.2-133.01) $\mu \mathrm{g} \cdot \mathrm{kg}^{-1}$, respectively. However, total concentration of inorganic arsenic in most of investigated rice samples was below the maximum residual level according to US-FDA and European Union standards. 


\section{Introduction}

Rice, especially white rice, is the most staple food in the diet of Vietnamese people. It is an indispensable ingredient of traditional meals in Vietnam as well as in some other Asian countries. In Vietnam, rice is the most common crop grown on agriculture land with total production of approximate 29 million tons in 2018, accounted for around $6 \%$ of the total rice production in the world, which puts Vietnam in the fourth position amongst the top rice producing countries, after China, India, and Bangladesh. [1] However, in some agricultural areas, rice is grown in flooded soil or water contaminated with arsenic compounds. Therefore, obtaining information about total arsenic concentration, especially concentration of arsenic species, is particularly important in assessing potential exposure risk of arsenic and its species to human health. The European Union and United State of American Food and Drug Administration approved a tolerance level of inorganic arsenic (iAs) as $0.2 \mathrm{mg} \cdot \mathrm{kg}^{-1}$ and $0.1 \mathrm{mg} \cdot \mathrm{kg}^{-1}$ for polished rice and rice-based products for infants and young children, respectively. The human exposure to arsenic compounds via rice consumption has been also investigated [2, 3]. In Vietnam, unfortunately, the reported data of arsenic in rice samples was very limited, especially for the concentration of arsenic species [4-6]. Therefore, it is necessary to have a selective, sensitivity, reliable, and validated analytical method for both total arsenic contents and its species in Vietnam rice samples.

Recently, many analytical methods have been introduced for quantification of arsenic species in the rice sample such as gas chromatography tandem mass spectrometry after appropriate derivatization steps, and liquid chromatography in combination with atomic absorption/fluorescence spectrometry (HPLC-AAS/AFS) [7, 8], liquid chromatography in combination with atomic absorption spectrometry via hydride generator (HPLC-HG-AAS), liquid chromatography in combination with inductively coupled plasma quadrupole mass spectrometry (HPLC-ICP-QMS) $[6,9,10]$, gas chromatography mass spectrometry, and gas chromatography atomic emission spectrometry have been also introduced for speciation analysis of arsenic compounds in ready-to-eat rice samples $[11,12]$. Moreover, a nonchromatographic separation was also introduced for analysis of inorganic arsenic in rice samples [13]. Among these methods, HPLC-ICP-QMS is the most popular for speciation analysis of arsenic compounds in both environmental and biological samples because of its selectivity, sensitivity, and flexibility [14-16].

In this work, speciation analysis of arsenic compounds was conducted on Vietnamese rice samples collected from rice fields in Red River Delta, especially in some contaminated soil areas. Arsenic species in rice samples were extracted with appropriate solvents and separated by anionexchange chromatography employed with gradient elution. Arsenic compounds were identified by both retention time on the anion-exchange column and arsenic monoxide tracer $\left(\mathrm{AsO}^{+} \mathrm{m} / z\right.$ 91) in ICP-DRC-QMS. In order to overcome isobaric mass interferences in ICP-DRC-QMS, dynamic reaction cell employed with oxygen gas was used. Ionization suppression or enhancement in HPLC-ICP-DRC-QMS for speciation of arsenic compounds was assessed via a postcolumn flow injector. All parameters of both anion exchange chromatography and inductively coupled plasma quadrupole mass spectrometry were optimized in order to achieve the highest selectivity and sensitivity. Fully validation of both total and speciation analysis of arsenic compounds was performed by using commercially available certified reference materials. Finally, the developed method was applied to speciation analysis of arsenic compounds in Vietnamese rice samples that were collected from some rice fields in Red River Delta of Vietnam.

\section{Materials and Methods}

2.1. Materials. Arsenobetaine (AsB, purity $\geq 95.0 \%$ ), cacodylic acid (dimethylarsinic acid: DMA, purity $\geq 98 \%$ ), and disodium methyl arsonate hexahydrate (monomethylarsonic acid, MMA, purity $\geq 98 \%$ ) were purchased form Sigma Aldrich (Singapore). Arsenite stock standard (As(III), $1000 \mathrm{mg} / \mathrm{L}$ as As) in $2 \% \mathrm{HCl}$ and arsenate stock standard (As(V), $1000 \mathrm{mg} / \mathrm{L}$ as As) in $\mathrm{H}_{2} \mathrm{O}$ were collected from PerkinElmer (USA). Nitric acid ( $\geq 65 \%$ ), ammonium carbonate (99.999\% trace metals basis), ammonium hydroxide solution $\left(28 \% \mathrm{NH}_{3}\right.$, purity $\geq 99.99 \%$ trace metals basis), disodium ethylenediaminetetraacetic acid (ACS reagent, purity 99.4-100.6\%, powder), methanol for HPLC (gradient grade, suitable as ACS-grade LC reagent, purity $\geq 99.9 \%$ ), and ethylenediaminetetraacetic acid disodium salt (EDTA, analytical grade) were purchased from Sigma Aldrich (Singapore). Deionized water (DIW), $18 \mathrm{M} \Omega \cdot \mathrm{cm}$, from Millipore Milli-Q system, was used for preparation of standard solutions, samples, and mobile phase solutions. Single arsenic stock solutions were prepared in DIW and kept at $-20^{\circ} \mathrm{C}$ in polypropylene tubes. Working solutions were fresh daily prepared by dilution of stock solutions in DIW. Certified Reference Material (CRM): arsenic in rice flour (ERM-BC211) from European Reference Materials, Institute for Reference Materials and Measurements (Geel, Belgium), which is certified for the concentration of inorganic arsenic and DMA, as well as total arsenic, was used for validation of the developed analytical method for speciation analysis of arsenic compounds in rice samples.

Mobile phase solution on channel A was prepared as follows: add $0.24 \mathrm{~g}\left(\mathrm{NH}_{4}\right)_{2} \mathrm{CO}_{3}$ and $0.025 \mathrm{~g}$ EDTA to a $1 \mathrm{~L}$ plastic HPLC reservoir containing $900 \mathrm{~g}$ DIW; next, adjust the $\mathrm{pH}$ to $9.00( \pm 0.05)$ with $28 \%$ ammonium hydroxide and then add $50 \mathrm{~mL}$ of methanol and finally fill to $1000 \mathrm{~g}$ with DIW. For channel B, $2.4 \mathrm{~g}\left(\mathrm{NH}_{4}\right)_{2} \mathrm{CO}_{3}$ and $0.025 \mathrm{~g}$ EDTA were added to a 1-liter plastic HPLC reservoir containing $990 \mathrm{~g}$ DIW, and the remaining steps were similar to the preparation of solution on channel A. Prior to use, all mobile phase solutions were filtered through a $0.45 \mu \mathrm{m}$ polyvinyldifluoride membrane filter and degassed by using ultrasonic bath. Mobile phase solutions were prepared fresh daily in order to minimize changes in $\mathrm{pH}$ caused by effects from the environment. 
2.2. Instruments. Separation of arsenic compounds was carried by an Altus ${ }^{\mathrm{TM}}$ A-30 UPLC ${ }^{\circledR}$ System (PerkinElmer, USA) including an Altus A-30 solvent delivery module (metal-free quaternary pump) and Altus A-30 sample injection (an autosampler equipped with a $100 \mu \mathrm{L}$ injection loop and silica-coated needle). It also has an online degasser and a column thermostat compartment. The HPLC system is controlled by Empower 3 version 7.0.3471.909 from Water Corporation (Water, MA, US). Arsenic compounds were separated on PRP-X100 strong anion-exchange column $(4.6 \times 150 \mathrm{~mm}, 5 \mu \mathrm{m}$ particle size; Hamilton, NV, USA) employed with gradient elution. Arsenic compounds were detected by NexION 2000 ICP-DRC-QMS (Perkin Elmer, USA) as a specific elemental detector. For detection, arsenic compounds eluting out of the strong anion-exchange column were directly sent to the ICP-DRC-QMS system via polyether ether ketone (PEEK) liquid chromatography tubing. The arsenic species were detected by arsenic monoxide $\left({ }^{75} \mathrm{As}^{16} \mathrm{O}^{+}, \mathrm{m} / z\right.$ 91) in dynamic reaction cell mode utilizing oxygen as the reaction gas. The identification of arsenic species was performed by comparing the retention times of single standards on RPR Hamilton X100 at the given chromatographic conditions and the tracer of ${ }^{75} \mathrm{As}^{16} \mathrm{O}^{+}$on the ICP-DRC-QMS. The sensitivity and selectivity of the ICP-DRC-QMS were daily checked by using specific tuning solution from PerkinElmer (N9303843, PerkinElmer, USA). Sensitivity of arsenic measurement was optimized and checked daily by using $10 \mathrm{ng} \cdot \mathrm{mL}^{-1} \mathrm{As}(\mathrm{V})$ standard solution (Merck, Singapore). The operating conditions of both HPLC and ICP-DRC-QMS are showed in Table 1.

\subsection{Collection and Preparation of Rice Samples for Speciation} Analysis. Rice samples were collected mainly from several provinces in Vietnam such as Hanam, Haiphong, and Nghe An. Some other samples were randomly collected in a supermarket in Hanoi. Total 23 samples were collected and transported to the laboratory for further pretreatment. Rice samples were rinsed with double distilled water to remove dust and then dried by air flow at room temperature. These samples were then freeze-dried at $-50^{\circ} \mathrm{C}$ in the FreeZone 4.5 Liter benchtop freeze dryers (Labconco, MO, USA). Next, rice was ground into powder by using a commercially available blender with stainless steel blades. Finally, the powdered rice samples were kept in sealed plastic bags at $4^{\circ} \mathrm{C}$ until analysis.

\subsection{Sample Preparation}

2.4.1. Total Analysis of Arsenic. $0.2 \mathrm{~g}$ of freeze-dried rice samples was weighed into a $75 \mathrm{~mL}$ Teflon microwave digestion vessel, and $6 \mathrm{~mL}$ of concentrated nitric acid was added. The vessel then was allowed to stand overnight. Afterward, the rice sample was digested in a microwave oven (Multiwave PRO $50 \mathrm{HZ}$ Package 24HVT8, Anton PAAR, Graz, Austria). The temperature program was increased up to $165^{\circ} \mathrm{C}$ in $15 \mathrm{~min}$ and then held at this temperature for a further $10 \mathrm{~min}$. In the second step of the digestion, the vessels were cooled to $50^{\circ} \mathrm{C}$ for $20 \mathrm{~min}$. After digestion, the samples were cooled to room temperature, transferred quantitatively into $50 \mathrm{~mL}$ volumetric flasks, and made up to volume with DIW. These solutions were then analyzed for the total arsenic content by ICP-DRC-QMS. Rice-based certified reference material (ERM BC-211) and fish-based certified reference materials (DORM 2, DORM 4, and BRC 627 ) were used for quality control and validation of the analytical method for total arsenic analysis.

2.4.2. Speciation Analysis. Rice samples preparation followed a procedure that was proposed by US-FDA with some modifications. In brief, $1.0 \mathrm{~g}$ of the ground rice was transferred into a $50 \mathrm{~mL}$ centrifuge tube. And then, $5 \mathrm{~mL}$ of $0.28 \mathrm{M} \mathrm{HNO}_{3}$ was added, followed by quick vortex mixing and rinsing the walls of the container with the another $5 \mathrm{~mL}$ of $0.28 \mathrm{M} \mathrm{HNO}_{3}$. Next, all tubes were capped tightly and placed in a preheated block digestion system at $95^{\circ} \mathrm{C}$ for $90 \mathrm{~min}$. After that, samples were let to cool and diluted by adding deionized water. Samples were then centrifuged at $1.3 \times 10^{4} \mathrm{~g}$ for $10 \mathrm{~min}$, and supernatants were filtered using a $0.45 \mu \mathrm{m}$ nylon syringe filter. These solutions were subjected for analysis via HPLC-ICP-DRC-QMS at the optimum operating conditions as follows. For quality control, rice-based matrix certificated reference material (ERM-BC 211 rice flour, European Union Breaux of Standard; Brussels) was prepared in the same manner as described above and analyzed at the same time. The extraction efficiency was calculated by comparing results between measurements and certified values. Practically, the number of quality control and blank samples accounted for $20 \%$ of the total sample subjected for analysis in both total and speciation analysis. The triplicates of sample and blank also included in the batch of analysis. For monitoring the carryover effect, blank sample that contained mobile phase was injected after every ten injections into HPLC-ICP-DRCQMS.

\section{Results and Discussions}

3.1. Total Arsenic in Rice Samples. Rice samples were digested in a microwave oven and analyzed for total concentration arsenic by ICP-DRC-MS using indium as an internal standard. In order to validate ICP-MS-based analytical method for quantification of total arsenic in real samples, three fishbased matrix and one rice-based matrix certified reference materials were used. $0.2 \mathrm{~g}$ of certificated reference materials (DORM 2 and DORM 4 from CRM Canada, ERM-BRC 627 from European Union) and rice-based certificated reference material (ERM-BC 211 from European Union) were aciddigested in a microwave oven and analyzed by using ICPDRC-QMS. The concentration of total arsenic in DORM 2, DORM 4, BRC-627, and ERM BC 211 was $17.3 \pm 0.3 \mathrm{mg} \cdot \mathrm{kg}^{-1}$, $7.13 \pm 0.1 \mathrm{mg} \cdot \mathrm{kg}^{-1}, 4.56 \pm 0.05 \mathrm{mg} \cdot \mathrm{kg}^{-1}$, and $255 \pm 12 \mu \mathrm{g} \cdot \mathrm{kg}^{-1}$, respectively. The certified total concentrations of arsenic are $18 \pm 1.1 \mathrm{mg} \cdot \mathrm{kg}^{-1}, 6.84 \pm 0.44 \mathrm{mg} \cdot \mathrm{kg}^{-1}, 4.8 \pm 0.3 \mathrm{mg} \cdot \mathrm{kg}^{-1}$, and $260 \pm 13 \mu \mathrm{g} \cdot \mathrm{kg}^{-1}$ for DORM 2, DORM 4, BRC-627, and ERM BC 211, respectively. The experimental results indicated that no significant difference was observed between measured and 
TABLE 1: Operating conditions of HPLC-ICP-DRC-QMS for speciation of arsenic compounds.

\begin{tabular}{|c|c|}
\hline \multicolumn{2}{|r|}{ Operating conditions of HPLC-ICP-DRC-QMS } \\
\hline \multicolumn{2}{|c|}{ High-performance liquid chromatography operating conditions } \\
\hline Pump & $\begin{array}{l}\text { Altus A-30 quaternary pump equipped with solenoid solvent selection valve, online degasser, liquid autosampler } \\
\text { with } 100 \mu \mathrm{L} \text { injection loop, and column temperature compartment }\end{array}$ \\
\hline Column & PRP X $100,4.6 \times 150 \mathrm{~mm}, 5 \mu \mathrm{m}$ particle size; Hamilton, NV, USA \\
\hline Column temperature & Room temperature $\left(\right.$ app. $\left.25^{\circ} \mathrm{C}\right)$ \\
\hline Eluent & $\begin{array}{c}\text { Channel A: } 5 \mathrm{mM}\left(\mathrm{NH}_{4}\right)_{2} \mathrm{CO}_{3}, \mathrm{pH} 9.0,0,05 \% \text { EDTA, } 5 \% \mathrm{MeOH} \\
\text { Channel B: } 50 \mathrm{mM}\left(\mathrm{NH}_{4}\right)_{2} \mathrm{CO}_{3}, \mathrm{pH} 9.0,0,05 \% \text { EDTA, 5\% } \mathrm{MeOH}\end{array}$ \\
\hline Elution mode & $\begin{array}{l}\text { Gradient elution: } 0-1 \text { minute: } 100 \% \mathrm{~A} \text { and then increasing linearly to } 100 \% \mathrm{~B} \text { in } 10 \text { minutes and kept for } 4 \text { minutes. } \\
\text { Finally decreasing to } 100 \% \text { in } 0.1 \text { minutes and kept for } 6 \text { minutes to regenerate column }\end{array}$ \\
\hline Flow rate & $1.0 \mathrm{~mL} \cdot \mathrm{min}^{-1}$ \\
\hline Injection volume & $50 \mu \mathrm{L}$ \\
\hline \multicolumn{2}{|c|}{ ICP-DRC-QMS operating conditions } \\
\hline RF power & $1600 \mathrm{~W}$ \\
\hline Plasma gas flow & $15 \mathrm{~L} \cdot \mathrm{min}^{-1}$ \\
\hline Auxiliary gas flow & $1.2 \mathrm{~L} \cdot \mathrm{min}^{-1}$ \\
\hline Nebulizer gas & $1 \mathrm{~L} \cdot \mathrm{min}^{-1}$ \\
\hline Nebulizer & PFA \\
\hline Spray chamber & Quartz cyclonic \\
\hline Sample cone & Platinum sample cone \\
\hline Skimmer cone & Platinum hyper skimmer cone \\
\hline Cell entrance voltage & $-7 \mathrm{~V}$ \\
\hline Cell exit voltage & $-7 \mathrm{~V}$ \\
\hline DRC mode & Dynamic reaction cell with oxygen gas, $0.7 \mathrm{~mL} \cdot \mathrm{min}^{-1}$ \\
\hline Monitored ion & $\mathrm{AsO}^{+}(\mathrm{m} / z$ 91) \\
\hline Measurement mode & Peak hopping \\
\hline Dwell time & $100 \mathrm{~ms}$ \\
\hline $\mathrm{RPq}$ & 0.6 \\
\hline Quantification mode & External calibration curve \\
\hline
\end{tabular}

certified values in this study. It should be noted that the ICPDRC-QMS-based analytical method in combination with microwave-assisted acidic digestion was the method that had an intended purpose for analysis of total arsenic in rice. Total concentration of arsenic in rice samples are listed in Table 2. As can be seen from this table, the concentration of arsenic in rice ranged from $124.6 \pm 9.8 \mu \mathrm{g} \cdot \mathrm{kg}^{-1}$ to $407 \pm 39.6 \mu \mathrm{g} \cdot \mathrm{kg}^{-1}$.

\subsection{High-Performance Liquid Chromatography for Separa-} tion of Arsenic Compounds. For speciation analysis of arsenic compounds, in this study, anion-exchange chromatography was directly combined with ICP-DRC-QMS via $60 \mathrm{~mm}$ PEEK tubing. Arsenic compounds were separated on an anion-exchange column (Hamilton PRP X100, 150 $\times$ $4.6 \mathrm{~mm} \times 5 \mu \mathrm{m}$ ) by employing with gradient of mobile phase compatible with mass spectrometry, including ammonium carbonate, EDTA, and methanol as organic modifiers. Arsenic compounds were detected via an arsenic monoxide tracer $\left({ }^{75} \mathrm{As}^{16} \mathrm{O}^{+}\right)$by ICP-DRC-QMS employed with oxygen as the reaction gas. The separation of five arsenic species in this work was modified from our previous studies $[17,18]$. In brief, five arsenic species were separated on the strong anion-exchange column with gradient of mobile phase, which was described as follows: the concentration of methanol and EDTA in the mobile phase was $5 \%$ and $0.05 \%$, respectively. The following mobile phase program is the optimum gradient for separation of five arsenic species. The concentration of ammonium carbonate ( $\mathrm{pH} 9.0$ ) was kept at $5 \mathrm{mM}$ for first one minute and linearly increased to $50 \mathrm{mM}(\mathrm{pH} 9.0)$ in the next 11 minutes. Then, it was kept at $50 \mathrm{mM}$ for 4 minutes before being decreased to $5 \mathrm{mM}$ in 0.1 minutes. Finally, the concentration of $5 \mathrm{mM}$ was kept for 6 minutes in order to regenerate the column for the next injection. Total time for chromatographic separation was 22 minutes. The flow rate of mobile phase was maintained constantly at $1 \mathrm{~mL} \cdot \mathrm{min}^{-1}$. Due to the fact that no structure information of arsenic compounds in ICP-DRC-QMS was obtained, identification of arsenic compounds was assessed via retention time on the Hamilton PRP X100 column and the data of arsenic monoxide tracer in ICP-DRC-QMS when analyzing single compounds under optimized conditions as described above.

As is illustrated in the chromatograph in Figure 1, five arsenic species were baseline separated under the optimum chromatographic conditions. The observed order of elution was AsB, As(III), DMA, MMA, and $\mathrm{As}(\mathrm{V})$ on the Hamilton PRP X-100 column. The resolution of all species ranged from 2.47 to 10.16 . It was worth noting that the chromatographic resolution of As(III) and DMA pair was 2.47. This information was so important because both As(III) and DMA were present in some rice samples as described in Table 2. Other critical parameters of the chromatographic separation including symmetry and peak width at baseline were also calculated according to European Pharmacopeia (Section 2.2.46 Chromatographic separation techniques) and listed in Table 3.

3.2.1. Column Recovery. For assessment of column recovery, the standard solutions containing five arsenic 
TABLE 2: Concentration ( $\mu \mathrm{g} \cdot \mathrm{kg}^{-1}$ dried weight, mean value $\pm \mathrm{SD}, n=3$ ) of arsenic species and total arsenic in rice samples.

\begin{tabular}{|c|c|c|c|c|c|c|c|c|c|}
\hline No. & $\begin{array}{l}\text { Sample } \\
\text { ID }\end{array}$ & $\begin{array}{l}\text { AsB or unretained } \\
\text { species }\end{array}$ & As(III) & DMA & MMA & $\mathrm{As}(\mathrm{V})$ & Total iAs* & Total $^{* *}$ & Total ${ }^{* * *}$ \\
\hline 1 & $\mathrm{R} 1$ & $41.04 \pm 1.22$ & $132.23 \pm 4.27$ & $133.01 \pm 4.80$ & $2.71 \pm 0.08$ & $53.62 \pm 5.59$ & $185.85 \pm 7.03$ & $362.84 \pm 17.91$ & $407.24 \pm 39.56$ \\
\hline 2 & $\mathrm{R} 2$ & $106.26 \pm 3.17$ & $101.35 \pm 3.27$ & $63.71 \pm 2.30$ & $2.99 \pm 0.09$ & $51.55 \pm 5.38$ & $152.9 \pm 6.3$ & $325.89 \pm 11.94$ & $353.24 \pm 19.75$ \\
\hline 3 & R3 & $30.29 \pm 0.9$ & $100.24 \pm 3.23$ & $38.47 \pm 1.39$ & $<\mathrm{LOD}$ & $1.13 \pm 0.12$ & $101.37 \pm 3.23$ & $170.62 \pm 5.3$ & $154.42 \pm 12.04$ \\
\hline 4 & $\mathrm{R} 4$ & $18.62 \pm 0.56$ & $99.36 \pm 3.21$ & $22.57 \pm 0.81$ & $2.83 \pm 0.09$ & $0.59 \pm 0.06$ & $99.95 \pm 3.21$ & $143.25 \pm 4.64$ & $140.11 \pm 10.93$ \\
\hline 5 & R5 & $15.9 \pm 0.47$ & $104.14 \pm 3.36$ & $59.44 \pm 2.14$ & $<\mathrm{LOD}$ & $0.43 \pm 0.05$ & $104.57 \pm 3.36$ & $180.26 \pm 5.95$ & $179.73 \pm 14.02$ \\
\hline 6 & R6 & $12.77 \pm 0.38$ & $8.97 \pm 0.29$ & $30.86 \pm 1.11$ & $<\mathrm{LOD}$ & $105.2 \pm 10.97$ & $114.17 \pm 11$ & $157.03 \pm 12.19$ & $148.5 \pm 11.58$ \\
\hline 7 & R7 & $<\mathrm{LOD}$ & $99.02 \pm 3.19$ & $36.39 \pm 1.31$ & $<\mathrm{LOD}$ & $38.9 \pm 4.06$ & $137.92 \pm 5.2$ & $174.31 \pm 8.38$ & $189.5 \pm 14.78$ \\
\hline 8 & $\mathrm{R} 8$ & $<\mathrm{LOD}$ & $12.03 \pm 0.39$ & $30.52 \pm 1.10$ & $<$ LOD & $100.6 \pm 10.49$ & $112.63 \pm 10.5$ & $143.14 \pm 11.77$ & $153.94 \pm 12.01$ \\
\hline 9 & R9 & $<\mathrm{LOD}$ & $79.47 \pm 2.56$ & $14.73 \pm 0.53$ & & $39.43 \pm 4.11$ & $118.9 \pm 4.84$ & $133.63 \pm 6.95$ & $142.68 \pm 11.13$ \\
\hline 10 & $\mathrm{R} 10$ & $<\mathrm{LOD}$ & $111.63 \pm 3.6$ & $17.68 \pm 0.64$ & $<\mathrm{LOD}$ & $65.73 \pm 6.86$ & $177.36 \pm 7.75$ & $195.04 \pm 10.84$ & $236.01 \pm 18.41$ \\
\hline 11 & $\mathrm{R} 11$ & $<\mathrm{LOD}$ & $93.94 \pm 3.03$ & $33.05 \pm 1.19$ & $<\mathrm{LOD}$ & $34.55 \pm 3.6$ & $128.49 \pm 4.71$ & $161.53 \pm 7.56$ & $169.83 \pm 13.25$ \\
\hline 12 & $\mathrm{R} 12$ & $<\mathrm{LOD}$ & $75.8 \pm 2.45$ & $8.71 \pm 0.31$ & $<\mathrm{LOD}$ & $63.39 \pm 6.61$ & $139.19 \pm 7.05$ & $147.91 \pm 9.18$ & $156.36 \pm 12.2$ \\
\hline 13 & $\mathrm{R} 13$ & $<\mathrm{LOD}$ & $94.63 \pm 3.05$ & $13.90 \pm 0.50$ & $<\mathrm{LOD}$ & $71.68 \pm 7.48$ & $166.31 \pm 8.1$ & $180.21 \pm 10.82$ & $187.56 \pm 14.63$ \\
\hline 14 & $\mathrm{R} 14$ & $<\mathrm{LOD}$ & $86.52 \pm 2.79$ & $46.66 \pm 1.68$ & $<\mathrm{LOD}$ & $71.03 \pm 7.41$ & $157.55 \pm 7.9$ & $204.21 \pm 11.68$ & $211.93 \pm 16.53$ \\
\hline 15 & R15 & $<\mathrm{LOD}$ & $84.35 \pm 2.72$ & $20.01 \pm 0.72$ & $<\mathrm{LOD}$ & $42.78 \pm 4.46$ & $127.13 \pm 5.2$ & $147.31 \pm 7.73$ & $151.02 \pm 11.78$ \\
\hline 16 & $\mathrm{R} 16$ & $<\mathrm{LOD}$ & $68.55 \pm 2.21$ & $26.16 \pm 0.94$ & $<\mathrm{LOD}$ & $52.14 \pm 5.44$ & $120.69 \pm 5.9$ & $146.85 \pm 8.38$ & $154.36 \pm 12.04$ \\
\hline 17 & $\mathrm{R} 17$ & $<\mathrm{LOD}$ & $93.5 \pm 3.02$ & $25.82 \pm 0.93$ & $<\mathrm{LOD}$ & $64.99 \pm 6.78$ & $158.49 \pm 7.4$ & $184.31 \pm 10.52$ & $191.87 \pm 14.97$ \\
\hline 18 & $\mathrm{R} 18$ & $<\mathrm{LOD}$ & $98.7 \pm 3.18$ & $41.72 \pm 1.50$ & $<\mathrm{LOD}$ & $129.31 \pm 13.49$ & $228.01 \pm 13.9$ & $269.73 \pm 18.02$ & $283.11 \pm 22.08$ \\
\hline 19 & R19 & $<\mathrm{LOD}$ & $84.55 \pm 12.07$ & $21.02 \pm 2.37$ & $<\mathrm{LOD}$ & $29.07 \pm 0.76$ & $113.62 \pm 12.1$ & $134.64 \pm 12.3$ & $283.90 \pm 22.23$ \\
\hline 20 & $\mathrm{R} 20$ & $<\mathrm{LOD}$ & $86.69 \pm 12.38$ & $10.88 \pm 1.23$ & $<\mathrm{LOD}$ & $43.53 \pm 1.14$ & $130.22 \pm 12.4$ & $141.1 \pm 12.5$ & $176.50 \pm 13.82$ \\
\hline 21 & $\mathrm{R} 21$ & $<\mathrm{LOD}$ & $57.19 \pm 8.16$ & $8.22 \pm 0.93$ & $<\mathrm{LOD}$ & $16.70 \pm 0.44$ & $73.89 \pm 8.2$ & $82.11 \pm 8.2$ & $124.60 \pm 9.76$ \\
\hline 22 & $\mathrm{R} 22$ & $<\mathrm{LOD}$ & $64.51 \pm 9.21$ & $21.27 \pm 2.40$ & $<\mathrm{LOD}$ & $0.98 \pm 0.03$ & $65.49 \pm 9.2$ & $86.76 \pm 9.5$ & $152.20 \pm 11.92$ \\
\hline 23 & $\mathrm{R} 23$ & $<\mathrm{LOD}$ & $78.20 \pm 11.16$ & $10.92 \pm 1.23$ & $<\mathrm{LOD}$ & $1.02 \pm 0.03$ & $79.22 \pm 11.2$ & $90.14 \pm 11.2$ & $150.70 \pm 11.80$ \\
\hline
\end{tabular}

${ }^{*}$ Total inorganic arsenic was calculated by sum of arsenite and arsenate; ${ }^{* *}$ total arsenic was calculated by sum up five species; ${ }^{* * *}$ total arsenic was determined by acidic digestion in the microwave oven and measured by total analysis.

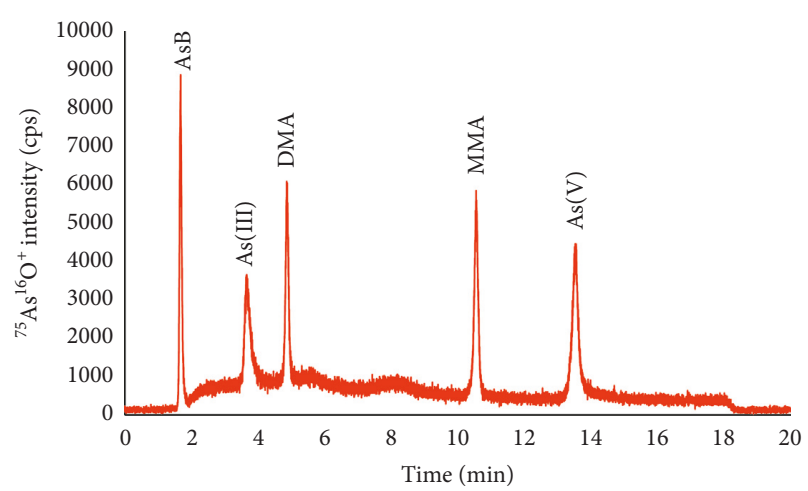

Figure 1: Chromatogram of five arsenic species separated on the Hamilton PRP-X100 strong anion-exchange column. Concentration of all species: $1 \mathrm{ng} \cdot \mathrm{mL}^{-1}$. Other experimental conditions are listed in Table 1.

species as well as five single standard solutions were injected into the HPLC-ICP-DRC-QMS system at the optimum experimental conditions. The same volume of standard solutions was injected into the ICP-DRC-QMS system at the same experimental operating conditions via a flow injector employed with $5 \mathrm{mM}$ of ammonium carbonate containing 5\% methanol as carrier. The column recovery of all species was calculated by dividing total peak area in LC-DRC-QMS by area of the peak obtained after flow injection into ICP-DRC-QMS. As can be seen from the results in Table 3, column recovery of five arsenic species was ranged from 85.3 to $98.9 \%$. It could be concluded that the elution strength of the selected mobile phase was strong enough to elute all species out of the analytical column. In addition, the selected mobile phase components showed the good separation and detection of all selected arsenic species in this study.

3.3. Optimization of ICP-DRC-QMS for Detection of Arsenic. Many analytical methods have been developed and introduced for quantitation of total arsenic content in environmental and biological samples. Among them, inductively coupled plasma quadrupole mass spectrometry is one of the most popular methods for total arsenic analysis because of its selectivity, sensitivity, multielement analysis, and isotope dilution analysis. However, the presence of interferences such as isobaric mass interferences or polyatomic mass interferences in ICP-QMS is common issue, which led them to be one of the critical parameters, especially in low-resolution mass spectrometry like quadrupole mass spectrometer, affected on the robustness of the analytical method. Many polyatomic ions, e.g., ${ }^{40} \mathrm{Ar}^{35} \mathrm{Cl}^{+},{ }^{59} \mathrm{Co}^{16} \mathrm{O}^{+},{ }^{36} \mathrm{Ar}^{38} \mathrm{Ar}^{1} \mathrm{H}^{+}$, ${ }^{38} \mathrm{Ar}^{37} \mathrm{Cl}^{+},{ }^{36} \mathrm{Ar}^{39} \mathrm{~K}^{+},{ }^{43} \mathrm{Ca}^{16} \mathrm{O}_{2}{ }^{+},{ }^{23} \mathrm{Na}^{12} \mathrm{C}^{40} \mathrm{Ar}^{+},{ }^{12} \mathrm{C}^{31} \mathrm{P}^{16} \mathrm{O}_{2}{ }^{+}$, are overlapped on the low-resolution mass spectrum of arsenic [19]. In this study, the PerkinElmer Nexion 2000 ICP-DRC-QMS system is equipped with three modes: standard/collision cell/dynamic reaction cell (DRC) was used for arsenic measurement. In DRC mode, oxygen gas was used as the reaction gas, and ${ }^{75} \mathrm{As}^{16} \mathrm{O}^{+}(\mathrm{m} / z$ 91) was monitored instead of the $\mathrm{As}^{+}(m / z 75)$ tracer. The most important parameter in DRC mode is reaction gas flow (or reaction gas pressure in dynamic reaction cell). For the assessment of the influence of gas flow on both total and 
TABLE 3: Characteristics of the chromatographic separation of arsenic species on the Hamilton PRP X100 column.

\begin{tabular}{lcccccc}
\hline No. & Analyte & $\begin{array}{c}\text { Retention time }(\mathrm{min}, \text { mean } \\
\text { value } \pm \mathrm{SD}, n=3)\end{array}$ & $\begin{array}{c}\text { Resolution (mean } \\
\text { value } \pm \mathrm{SD}, n=3)\end{array}$ & $\begin{array}{c}\text { Symmetry (mean } \\
\text { value } \pm \mathrm{SD}, n=3)\end{array}$ & $\begin{array}{c}W \text { (min, mean } \\
\text { value } \pm \mathrm{SD}, n=3)\end{array}$ & $\begin{array}{c}\text { Column recovery } \\
(\%, \text { value } \pm \mathrm{SD}, n=3)\end{array}$ \\
\hline 1 & AsB & $2.00 \pm 0.15$ & - & $1.51 \pm 0.14$ & $0.410 \pm 0.033$ & $85.3 \pm 1.0$ \\
2 & As(III) & $3.54 \pm 0.25$ & $2.97 \pm 0.11$ & $2.01 \pm 0.27$ & $0.560 \pm 0.019$ & $95.6 \pm 0.5$ \\
3 & DMA & $5.10 \pm 0.10$ & $2.47 \pm 0.35$ & $1.29 \pm 0.18$ & $0.488 \pm 0.052$ & $86.7 \pm 1.5$ \\
4 & MMA & $10.53 \pm 0.01$ & $10.16 \pm 0.26$ & $0.86 \pm 0.02$ & $0.623 \pm 0.040$ & $97.9 \pm 2.1$ \\
5 & As(V) & $14.06 \pm 0.03$ & $5.25 \pm 0.24$ & $0.99 \pm 0.10$ & $0.842 \pm 0.032$ & $98.9 \pm 0.5$ \\
\hline
\end{tabular}

Resolution $=1.18 *\left(t_{\mathrm{R} 2}-t_{\mathrm{R} 1}\right) / w_{\mathrm{h} 1}+w_{\mathrm{h} 2} ;$ symmetry $=w_{0.05} / 2 * d$ according to European Pharmacopeia.

speciation analyses, the oxygen flow was changed from 0.5 to $0.9 \mathrm{~mL} \cdot \mathrm{min}^{-1}$ to $0.1 \mathrm{~mL} \cdot \mathrm{min}^{-1} \mathrm{step}$. The optimum flow of oxygen was obtained at $0.7 \mathrm{~mL} \cdot \mathrm{min}^{-1}$ for both sensitivity and repeatability. Therefore, flow of oxygen gas was kept at $0.7 \mathrm{~mL} \cdot \mathrm{min}^{-1}$ for further experiments.

\subsubsection{Ionization Effect in Inductively Coupled Plasma.} For investigation of the ionization enhancement and suppression in plasma employed with high carbon content mobile phase, a $100 \mathrm{ng} \cdot \mathrm{mL}^{-1}$ solution of arsenate in $2 \%$ nitric acid (Merck, Singapore) was used. The postcolumn injection was performed manually via a postcolumn injector every two minutes. The postcolumn injector and instrumental setup were more detailed in the previous work [20]. The species-unspecific solution was injected every two minutes, using the eluent containing only deionized water or gradient of mobile phase. The transient signals of these experiments in water and mobile phase are depicted in Figures 2(a) and 2(b), respectively.

It is clear from Figure 2(a) that the signal of the analyte was kept constant for the whole time of chromatographic separation process if deionized water was used as carrier. Meanwhile, in Figure 2(b), the analytical signal was strongly dependent on the gradient of the mobile phase (gradient of concentration of ammonium carbonate in the mobile phase) during chromatographic separation time. When the concentration of ammonium carbonate in mobile phase was low, the analytical intensity of arsenic was high. In contrast, when higher concentration of ammonium carbonate in mobile phase was applied, the lower analytical intensity was observed. It could be attributed to the increase of carbon in plasma that can change the physiochemical properties of plasma (Figure 2(b)). In addition, the analytical signal of the target analyte (peak area and peak height) in the mobile phase was enhanced at least 2 to 4 times higher than that in deionized water. It could be explained by the enhancement of analytical signal in the presence of carbon in the plasma source, which led to a phenomenon known as charge transfer reaction between the target analyte and $\mathrm{C}^{+}$or $\mathrm{ArC}^{+}$. This effect occurred in the plasma source as proposed by Kovačevič et al. [21-23].

3.3.2. Analytical Figure of Merits of the HPLC-ICP-DRCQMS for Speciation Analysis of Arsenic Compounds. Table 3 lists the chromatographic characteristics of the optimized method, such as retention time, chromatographic resolution peak symmetric, and peak width at baseline according to European Pharmacopeia. Other critical parameters of the developed method are repeatability of the retention time and analytical signal (peak area). For the assessment of short-term stability of the retention time and peak area, three independent solutions of five arsenic species were freshly prepared in deionized water and injected into the HPLC-ICP-DRC-QMS system. For long-term stability, one mixture of five arsenic species was prepared and continuously measured for 20 hours in HPLC-ICP-DRCQMS. Relative standard deviation of retention time and peak area of all arsenic species was calculated and listed in Table 4 . The stability of retention time was achieved in the range of $0.2-3.0 \%$ (short term, $n=3$ ) and $0.15-6.76 \%$ (long-term stability) for all AsB, As(III), DMA, MMA, and $\mathrm{As}(\mathrm{V})$. The experimental results demonstrated that the excellent repeatability of retention time was achieved for separation of arsenic species via anion-exchange chromatography. However, the retention time shift was observed after approximately 100 injections of samples (especially real samples). Therefore, in this case, the column was regenerated by back flush overnight using a solvent as per the suggestion of the manufacturer. The repeatability of analytical signal is a parameter that has a significant contribution on the uncertainty of measurements. The repeatability of peak areas of all arsenic species was assessed by injecting an arsenic standard mixture solution at different times. Relative standard deviations of peak areas of five arsenic compounds were in the range of $2-16 \%$ and $4-17 \%$ for short-term and long-term stability, respectively. It was worth noting that the good repairability of peak areas was achieved in this study.

Other parameters of the analytical method are limit of detection and limit of quantitation. For the assessment of LOD and LOQ of the introduced method, six standard solutions with concentration of all arsenic species from 0.5 to $10 \mathrm{ng} \cdot \mathrm{mL}^{-1}$ were prepared and injected in triplicate into HPLC-ICP-DRC-MS systems. The calibration functions were calculated by linear regression, based on average peak areas and concentration of the target analyte. LOD and LOQ were calculated as the concentration at the signal-to-noise ratio of 3 and 10, respectively, according to US-FDA guidance and other works [24-29].

As can be seen from Table 5, the excellent correlation between analytical signal and concentration of arsenic species was achieved. LOD and LOQ of the developed method were high enough for directly analysis of arsenic species in rice samples. Absolute LOD and LOQ of the developed method were achieved at picogram levels. LOD and LOQ of the developed method were also comparable with recent publications $[9,30]$. In summary, the introduced 


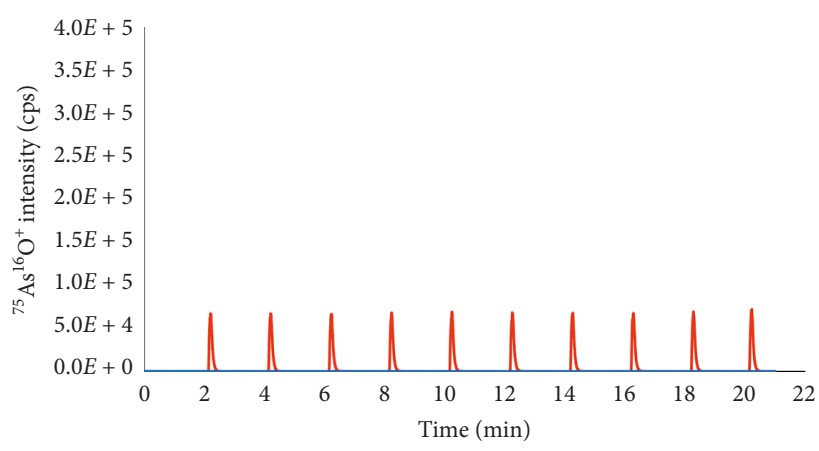

(a)

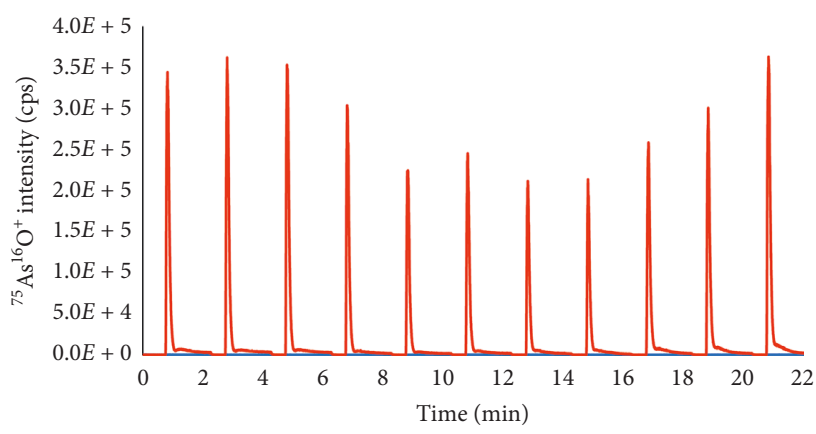

(b)

FIGURE 2: Flow injection transient signals of arsenic intensity performed via a species-unspecific postcolumn injector. The blue and red lines present blank and transient signals of the analyte in both figures. (a) Transient signal of arsenic (As(V)) in deionized water as the carrier; (b) transient signal of arsenic $(\mathrm{As}(\mathrm{V}))$ in gradient of mobile phase as the carrier.

TABLE 4: Short-term and long-term stability of retention times and peak areas.

\begin{tabular}{|c|c|c|c|c|c|c|}
\hline \multirow[b]{2}{*}{ No. } & \multirow[b]{2}{*}{ Analyte } & \multicolumn{3}{|c|}{ Retention time } & \multicolumn{2}{|c|}{ Peak area } \\
\hline & & $\begin{array}{l}\text { Mean value (min), } \\
n=3\end{array}$ & $\begin{array}{l}\text { RSD of short-term (\%), } \\
\qquad n=3\end{array}$ & RSD of long-term (\%), & $\begin{array}{l}\text { RSD of short-term (\%), } \\
\qquad n=3\end{array}$ & RSD of long-term (\%) \\
\hline 1 & AsB & 2.00 & 1.28 & 6.76 & 15.92 & 16.66 \\
\hline 2 & As(III) & 3.54 & 3.02 & 3.36 & 14.28 & 14.57 \\
\hline 3 & DMA & 5.10 & 1.99 & 2.80 & 11.29 & 12.65 \\
\hline 4 & MMA & 10.53 & 0.13 & 0.15 & 2.86 & 4.19 \\
\hline 5 & $\mathrm{As}(\mathrm{V})$ & 14.06 & 0.19 & 0.40 & 2.63 & 8.03 \\
\hline
\end{tabular}

TABLE 5: Analytical figure of merits of speciation analysis of five arsenic species in HPLC-ICP-DRC-QMS.

\begin{tabular}{|c|c|c|c|c|c|c|c|}
\hline No. & Analyte & Regression equation & $R^{2}$ & $\begin{array}{c}\mathrm{LOD}\left(\mathrm{ng}^{-1}\right)(\text { mean } \\
\text { value } \pm \mathrm{SD}, n=3)\end{array}$ & $\begin{array}{c}\text { LOQ }\left(\mathrm{ng}^{-1}\right)(\text { mean } \\
\text { value } \pm S D, n=3)\end{array}$ & $\begin{array}{l}\mathrm{LOD}^{\mathrm{a}}(\mathrm{pg})(\text { mean } \\
\text { value } \pm \mathrm{SD}, n=3)\end{array}$ & $\begin{array}{l}\mathrm{LOQ}^{\mathrm{a}}(\mathrm{pg})(\text { mean } \\
\text { value } \pm \mathrm{SD}, n=3)\end{array}$ \\
\hline 1 & AsB & $\begin{array}{c}y=(83200 \pm 1300) * \\
x-(63400 \pm 56500)\end{array}$ & 0.9988 & $0.5 \pm 0.1$ & $1.7 \pm 0.3$ & $25.8 \pm 4.2$ & $85.9 \pm 13.9$ \\
\hline 2 & As(III) & $\begin{array}{l}y=(48900 \pm 600) * \\
x-(35100 \pm 28200)\end{array}$ & 0.9991 & $2.9 \pm 0.3$ & $9.6 \pm 0.9$ & $144.2 \pm 46.2$ & $480.6 \pm 154$ \\
\hline 3 & DMA & $\begin{array}{l}y=(52900 \pm 700) * \\
x-(44200 \pm 32300)\end{array}$ & 0.9990 & $0.7 \pm 0.2$ & $2.4 \pm 0.6$ & $36.0 \pm 8.5$ & $119.8 \pm 28.5$ \\
\hline 4 & MMA & $\begin{array}{l}y=(49000 \pm 700) * \\
x+(41600 \pm 15700)\end{array}$ & 0.9992 & $0.9 \pm 0.1$ & $3.1 \pm 0.4$ & $46.1 \pm 5.6$ & $153.8 \pm 18.6$ \\
\hline 5 & $\operatorname{As}(\mathrm{V})$ & $\begin{array}{c}y=(56100 \pm 300) * \\
x+(9600 \pm 13600)\end{array}$ & 0.9998 & $0.9 \pm 0.2$ & $2.9 \pm 0.6$ & $42.8 \pm 9.0$ & $146.0 \pm 30$ \\
\hline
\end{tabular}

absolute amount of the analyte injected into the column.

and optimized method was fit-for-purpose regarding the quantification of arsenic compounds in rice samples.

3.3.3. Interconversion during Sample Preparation. For investigation of conversion during the sample preparation, spiking experiments were carried out by adding standard solutions into rice samples before extraction. Five single standard solutions of each arsenic compounds at the concentration of $20 \mathrm{ng} \cdot \mathrm{mL}^{-1}$ was used for spiking experiments. The results have shown that only conversion of As(III) to $\mathrm{As}(\mathrm{V})$ was observed (approximate $30 \%$ of As(III) changed to $\mathrm{As}(\mathrm{V})$ in such experimental conditions). The conversion of As(III) to As(V) was also confirmed in the work of Narukawa et al. [31]. However, it could not be affected on the total concentration of inorganic arsenic in rice samples because it was calculated by the sum of concentration of As(III) to As(V).

3.4. Validation of the Developed Method. The full validation of the developed method is performed by either comparison with another validated method or using certified reference material according to Guidance from United Stated Food and Drug Administration. In this study, the validation was carried out by using rice-based ERM-BC211 certified reference material from European Reference Materials. The ERM-BC211 was prepared and analyzed at the optimum conditions for both approaches: total and speciation 
analysis. The HPLC-ICP-DRC-QMS chromatogram of the ERM-BC211 is depicted in Figure 3, and the concentration of total arsenic and arsenic species is shown in Table 6.

As clearly shown in Table 6, experimental results and certified values of both total and species concentration of arsenic indicated the good agreement between them in this work. It is concluded that the introduced method was fit-forpurpose for quantitation of total and speciation analysis of arsenic compounds in rice. In addition, the extraction efficiency of other arsenic compounds like AsB and MMA that do not present in the certified reference material was calculated by spiking experiments. Rice samples were spiked with $20 \mathrm{ng} \cdot \mathrm{g}^{-1}$ standard mixture solution of five arsenic species and treated in the same manner as described above. Recovery of AsB, As(III), DMA, MMA, and As(V) was $105 \%, 70 \%, 108 \%, 98.4 \%$, and $135.5 \%$, respectively. The lower recovery of arsenite in rice samples was explained by interconversion during sample preparation as mentioned above and proposed in the published work [32]. Nevertheless, total inorganic arsenic content in rice samples was calculated by summing up concentration of arsenite and arsenate. Therefore, interconversion of arsenite to arsenate did not affect the quantitation of total inorganic arsenic content in rice samples.

3.5. Analysis of Arsenic Compounds in Rice Samples. For the application of the proposed method, total 23 rice samples were collected and analyzed as the aforementioned protocol. The representative chromatogram of arsenic compounds in rice samples is indicated in Figure 4.

The concentration of arsenic species as well as total arsenic determined by ICP-DRC-MS after acidic digestion in the microwave oven in rice samples are demonstrated in Table 6. Total inorganic arsenic was calculated by the sum of $\mathrm{As}(\mathrm{III})$ and $\mathrm{As}(\mathrm{V})$.

As can be seen from Table 2, three arsenic species, $\mathrm{As}(\mathrm{III}), \mathrm{DMA}$, and $\mathrm{As}(\mathrm{V})$, were detected in all rice samples. AsB or unretained species like tetramethylarsonium and MMA were found at low concentration in only few samples. The presence of tetramethylarsonium in rice samples which contained elevated arsenic concentration was also found by Hansen et al. [33] or it can be the product of interaction between arsenic species with mobile phase [34]. Percentage of inorganic arsenic compounds was calculated by dividing total inorganic arsenic by total arsenic content analyzed by ICP-DRC-MS after acidic digestion in the microwave oven. The percentage of inorganic arsenic (iAs) and DMA in all rice samples ranged from 46.9 to $94.1 \%$ and from 7.7 to $36.7 \%$, respectively. The mean values and corresponding standard deviation of As(III), DMA, As(V), and iAs in all analyzed rice samples were $83.3 \pm 28.1,32 \pm 26.7,46.9 \pm 35.5$, and $130.2 \pm 67.8 \mu \mathrm{g} \cdot \mathrm{kg}^{-1}$, respectively. Concentration of iAs was found higher than $200 \mu \mathrm{g} \cdot \mathrm{kg}^{-1}$ in only one rice sample (R18), and it could be explained that this sample was taken from rice field nearby mining activity area. However, concentration of iAs in rice samples was most below maximum residual level according to US-FDA and European Union standards $[35,36]$.

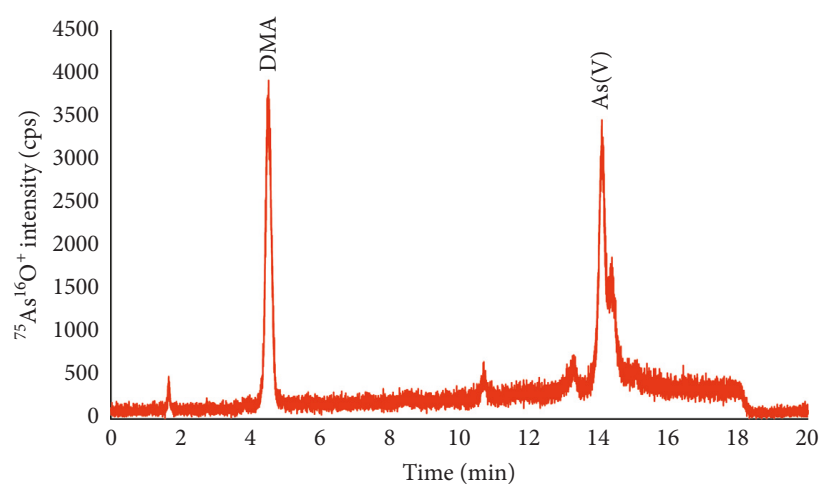

FIgURE 3: HPLC-ICP-DRC-QMS chromatogram of arsenic species in certified reference materials ERM-BC 211.

TABLE 6: Concentration of arsenic species and total concentration in certified reference material (ERM-BC 211).

\begin{tabular}{lccc}
\hline & & \multicolumn{2}{c}{ Concentration $\left(\mu \mathrm{g} \cdot \mathrm{kg}^{-1}\right)$} \\
No. & Analyte & $\begin{array}{c}\text { Experimental results } \\
(\text { mean value } \pm \mathrm{SD}, \\
n=5)\end{array}$ & $\begin{array}{c}\text { Certified valued } \\
\text { (certified value } \pm \mathrm{U}, k=2)\end{array}$ \\
\hline 1 & DMA & $123.45 \pm 4.45$ & $119 \pm 13$ \\
2 & As(III) & $<\mathrm{LOD}$ & $\mathrm{nc}^{\mathrm{a}}$ \\
3 & As(V) & $134.79 \pm 10.93$ & $\mathrm{nc}^{\mathrm{a}}$ \\
4 & Total & $134.79 \pm 10.93$ & $124 \pm 11$ \\
5 & iAs & $258.95 \pm 16.05$ & $260 \pm 13$ \\
\hline
\end{tabular}

${ }^{\mathrm{a}}$ Concentration of $\mathrm{As}(\mathrm{III})$ and $\mathrm{As}(\mathrm{V})$ is not shown in the certification of analysis of ERM-BC 211.

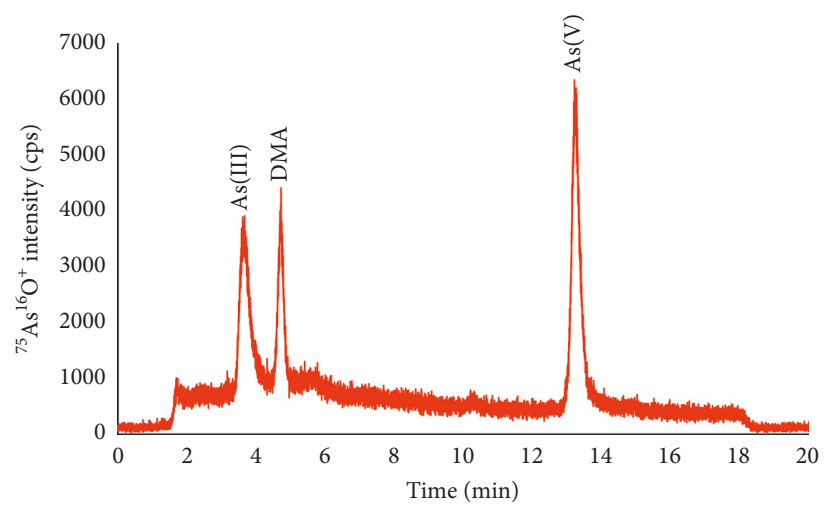

FIGURE 4: HPLC-ICP-DRC-QMS chromatogram of arsenic species in rice samples.

\section{Conclusion}

In this work, a high-performance liquid chromatography in combination with inductively coupled plasma dynamic reaction cell mass spectrometry has been successfully introduced and optimized for speciation analysis of arsenic compounds in rice samples. The analytical signal of arsenic during chromatographic separation was also investigated via a postcolumn injector. The experimental results demonstrated that the analytical signal of arsenic strongly depended 
on the gradient of mobile phase. The developed method has been fully validated by rice-based certificated reference material. This validated analytical method was used for analysis of arsenic species in 23 rice samples collected from rice fields in Red River Delta, Vietnam. Two inorganic arsenic species including arsenite and arsenate were found in some rice samples. However, total inorganic arsenic in the most samples was below US-FDA and EU standards. In the next study, assessment of human exposure to arsenic species through rice consumption and other sources, e.g., water and fish-based food, will be presented.

\section{Data Availability}

The LC-ICP-DRC-MS chromatograms and all data used to support the findings of this study are available from the corresponding author upon request.

\section{Conflicts of Interest}

The authors declare that they have no conflicts of interest.

\section{Acknowledgments}

This research was funded by the Vietnam National Foundation for Science and Technology Development (NAFOSTED) under grant number 104.04-2017.19.

\section{References}

[1] Overview for 2018/19, 2018, https://apps.fas.usda.gov/ psdonline/circulars/grain-rice.pdf.

[2] H. Rasheed, P. Kay, R. Slack, and Y. Y. Gong, "Arsenic species in wheat, raw and cooked rice: exposure and associated health implications," Science of the Total Environment, vol. 634, pp. 366-373, 2018.

[3] M. A. Davis, A. J. Signes-Pastor, M. Argos et al., "Assessment of human dietary exposure to arsenic through rice," Science of the Total Environment, vol. 586, pp. 1237-1244, 2017.

[4] T. D. Phuong, S. Kokot, P. V. Chuong, and D. Tong Khiem, "Elemental content of Vietnamese rice part 1: sampling, analysis and comparison with previous studies," The Analyst, vol. 124, no. 4, pp. 553-560, 1999.

[5] S. Kokot and T. Dong Phuong, "Elemental content of Vietnamese rice. Part 2: multivariate data analysis," The Analyst, vol. 124, no. 4, pp. 561-569, 1999.

[6] S. Nookabkaew, N. Rangkadilok, C. Mahidol, G. Promsuk, and J. Satayavivad, "Determination of arsenic species in rice from Thailand and other Asian countries using simple extraction and HPLC-ICP-MS analysis," Journal of Agricultural and Food Chemistry, vol. 61, no. 28, pp. 6991-6998, 2013.

[7] C. Wei and J. Liu, "A new hydride generation system applied in determination of arsenic species with ion chromatographyhydride generation-atomic fluorescence spectrometry (ICHG-AFS)," Talanta, vol. 73, no. 3, pp. 540-545, 2007.

[8] S. Simon, H. Tran, F. Pannier, and M. Potin-Gautier, "Simultaneous determination of twelve inorganic and organic arsenic compounds by liquid chromatography-ultraviolet irradiation-hydride generation atomic fluorescence spectrometry," Journal of Chromatography A, vol. 1024, no. 1-2, pp. 105-113, 2004.
[9] T. Narukawa, K. Chiba, S. Sinaviwat, and J. Feldmann, “A rapid monitoring method for inorganic arsenic in rice flour using reversed phase-high performance liquid chromatographyinductively coupled plasma mass spectrometry," Journal of Chromatography A, vol. 1479, pp. 129-136, 2017.

[10] S. H. Son, W. B. Lee, D. Kim, Y. Lee, and S. H. Nam, "An alternative analytical method for determining arsenic species in rice by using ion chromatography and inductively coupled plasma-mass spectrometry," Food Chem.vol. 270, pp. 353358, 2019.

[11] M. Y. Jung, J. H. Kang, H. J. Jung, and S. Y. Ma, "Inorganic arsenic contents in ready-to-eat rice products and various Korean rice determined by a highly sensitive gas chromatographytandem mass spectrometry," Food Chem.vol. 240, pp. 1179-1183, 2018.

[12] N. Campillo, R. Penalver, P. Vinas, I. Lopezgarcia, and M. Hernandezcordoba, "Speciation of arsenic using capillary gas chromatography with atomic emission detection," Talanta, vol. 77, no. 2, pp. 793-799, 2008.

[13] G. M. dos Santos, D. Pozebon, C. Cerveira, and D. P. de Moraes, "Inorganic arsenic speciation in rice products using selective hydride generation and atomic absorption spectrometry (AAS)," Microchemical Journal, vol. 133, pp. 265-271, 2017.

[14] J. L. Gómez-Ariza, D. Sánchez-Rodas, I. Giráldez, and E. Morales, "A comparison between ICP-MS and AFS detection for arsenic speciation in environmental samples," Talanta, vol. 51, no. 2, pp. 257-268, 2000.

[15] W. A. Maher, M. J. Ellwood, F. Krikowa, G. Raber, and S. Foster, "Measurement of arsenic species in environmental, biological fluids and food samples by HPLC-ICPMS and HPLC-HG-AFS," Journal of Analytical Atomic Spectrometry, vol. 30, no. 10, pp. 2129-2183, 2015.

[16] M. Marcinkowska and D. Barałkiewicz, "Multielemental speciation analysis by advanced hyphenated technique-HPLC/ ICP-MS: a review," Talanta, vol. 161, pp. 177-204, 2016.

[17] M. H. Nguyen, Q. T. Tran, H. T. Nguyen et al., "Speciation analyis of arsenic compounds in marine fish by HPLC-ICPMS," Vietnam Journal of Chemistry, vol. 55, no. 3, pp. 94-98, 2017.

[18] M. H. Nguyen, T. D. Pham, T. L. Nguyen et al., "Speciation analysis of arsenic compounds by HPLC-ICP-MS: application for human serum and urine," Journal of Analytical Methods in Chemistry, vol. 2018, Article ID 9462019, 8 pages, 2018.

[19] T. W. May and R. H. Wiedmeyer, "A table of polyatomic interferences in ICP-MS," Atomic Spectroscopy, vol. 19, no. 5, pp. 150-155, 1998.

[20] D. B. Chu, K. Klavins, G. Koellensperger, and S. Hann, "Speciation analysis of sugar phosphates via anion exchange chromatography combined with inductively coupled plasma dynamic reaction cell mass spectrometry-optimization for the analysis of yeast cell extracts," Journal of Analytical Atomic Spectrometry, vol. 29, no. 5, p. 915, 2014.

[21] M. Kovačevič and W. Goessler, "Direct introduction of volatile carbon compounds into the spray chamber of an inductively coupled plasma mass spectrometer: sensitivity enhancement for selenium," Spectrochimica Acta Part B: Atomic Spectroscopy, vol. 60, no. 9-10, pp. 1357-1362, 2005.

[22] G. Grindlay, J. Mora, M. De Loos-Vollebregt, and F. Vanhaecke, "A systematic study on the influence of carbon on the behavior of hard-to-ionize elements in inductively coupled plasma-mass spectrometry," Spectrochimica Acta Part B: Atomic Spectroscopy, vol. 86, pp. 42-49, 2013.

[23] G. Grindlay, L. Gras, J. Mora, and M. T. C. De LoosVollebregt, "Carbon-, sulfur-, and phosphorus-based charge 
transfer reactions in inductively coupled plasma-atomic emission spectrometry," Spectrochimica Acta Part B: Atomic Spectroscopy, vol. 115, pp. 8-15, 2016.

[24] U.S. Department of Health and Human Services Food and Drug Administration," Guidance for Industry Bioanalytical Method Validation, FDA, Silver Spring, MD, USA, 2001.

[25] F. T. Peters, O. H. Drummer, and F. Musshoff, "Validation of new methods," Forensic Science International, vol. 165, no. 23, pp. 216-224, 2007.

[26] H. Evard, A. Kruve, and I. Leito, "Tutorial on estimating the limit of detection using LC-MS analysis, part I: theoretical review," Analytica Chimica Acta, vol. 942, pp. 23-39, 2016.

[27] A. Kruve, R. Rebane, K. Kipper et al., "Tutorial review on validation of liquid chromatography-mass spectrometry methods: part II," Analytica Chimica Acta, vol. 870, pp. 8-28, 2015.

[28] H. Evard, A. Kruve, and I. Leito, "Tutorial on estimating the limit of detection using LC-MS analysis, part II: practical aspects," Analytica Chimica Acta, vol. 942, pp. 40-49, 2016.

[29] A. Kruve, R. Rebane, K. Kipper et al., "Tutorial review on validation of liquid chromatography-mass spectrometry methods: part I," Analytica Chimica Acta, vol. 870, no. 1, pp. 29-44, 2015.

[30] E.-M. Rintala, P. Ekholm, P. Koivisto, K. Peltonen, and E.-R. Venäläinen, "The intake of inorganic arsenic from long grain rice and rice-based baby food in Finland-low safety margin warrants follow up," Food Chemistry, vol. 150, pp. 199-205, 2014.

[31] T. Narukawa, K. Inagaki, T. Kuroiwa, and K. Chiba, "The extraction and speciation of arsenic in rice flour by HPLCICP-MS," Talanta, vol. 77, no. 1, pp. 427-432, 2008.

[32] M. Welna, A. Szymczycha-Madeja, and P. Pohl, "Comparison of strategies for sample preparation prior to spectrometric measurements for determination and speciation of arsenic in rice," TrAC Trends in Analytical Chemistry, vol. 65, pp. 122136, 2015.

[33] H. R. Hansen, A. Raab, A. H. Price et al., "Identification of tetramethylarsonium in rice grains with elevated arsenic content," Journal of Environmental Monitoring, vol. 13, no. 1, pp. 32-34, 2011.

[34] J.-H. Huang, G. Ilgen, and B. Decker, "Sample pre-treatment to eliminate cationic methylated arsenic for determining arsenite on an anion-exchange column by high performance liquid chromatography-inductively coupled plasma mass spectrometry," Analytica Chimica Acta, vol. 611, no. 1, pp. $48-55,2008$.

[35] FDA, "Press announcements-FDA proposes limit for inorganic arsenic in infant rice cereal, 2017, https://www.fda.gov/ NewsEvents/Newsroom/PressAnnouncements/ucm493740. htm.

[36] COMMISSION REGULATION (EU) 2015/1006 of 25 June 2015 amending Regulation (EC) No 1881/2006 as regards maximum levels of inorganic arsenic in foodstuffsand, https:// eur-lex.europa.eu/legal-content/EN/TXT/?uri=OJ:JOL_2015_ 161_R_0006. 

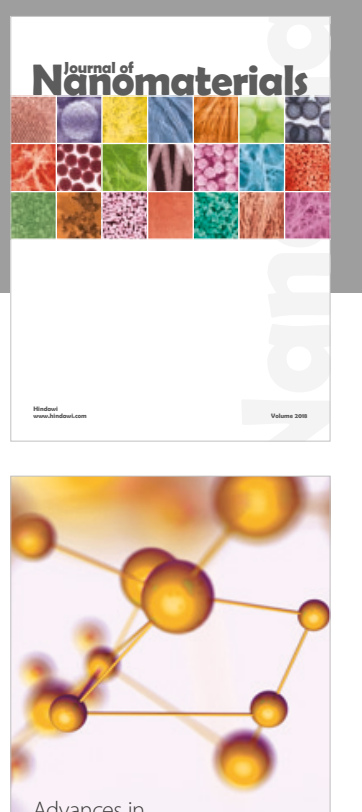

Physical Chemistry
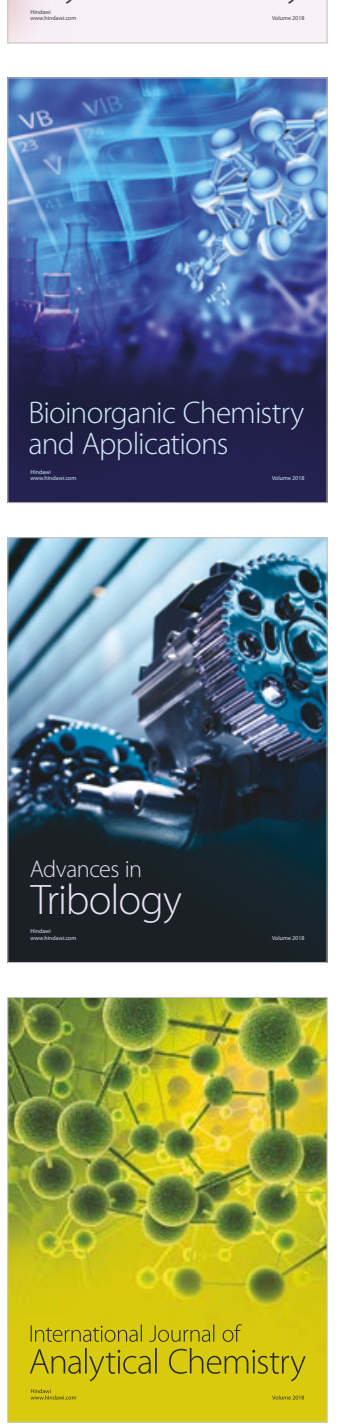

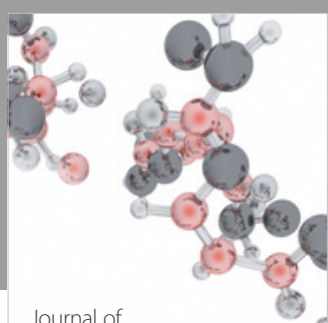

Analytical Methods

in Chemistry

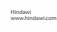

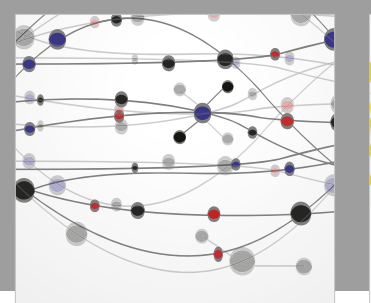

The Scientific World Journal

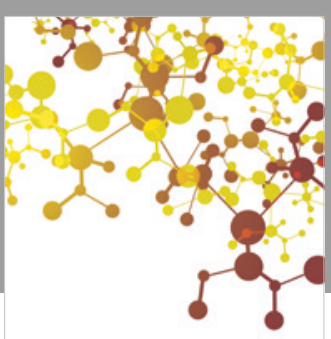

Journal of

Applied Chemistry
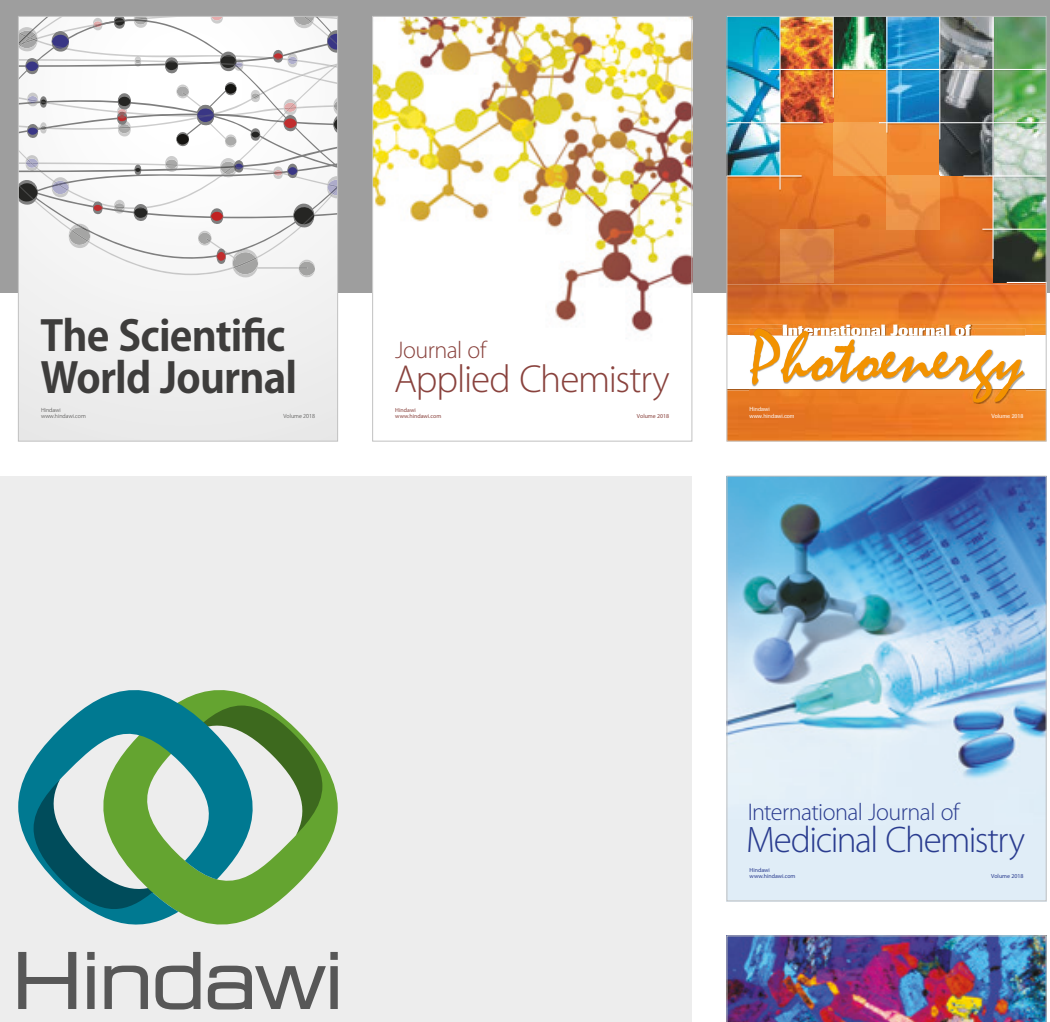

Submit your manuscripts at

www.hindawi.com
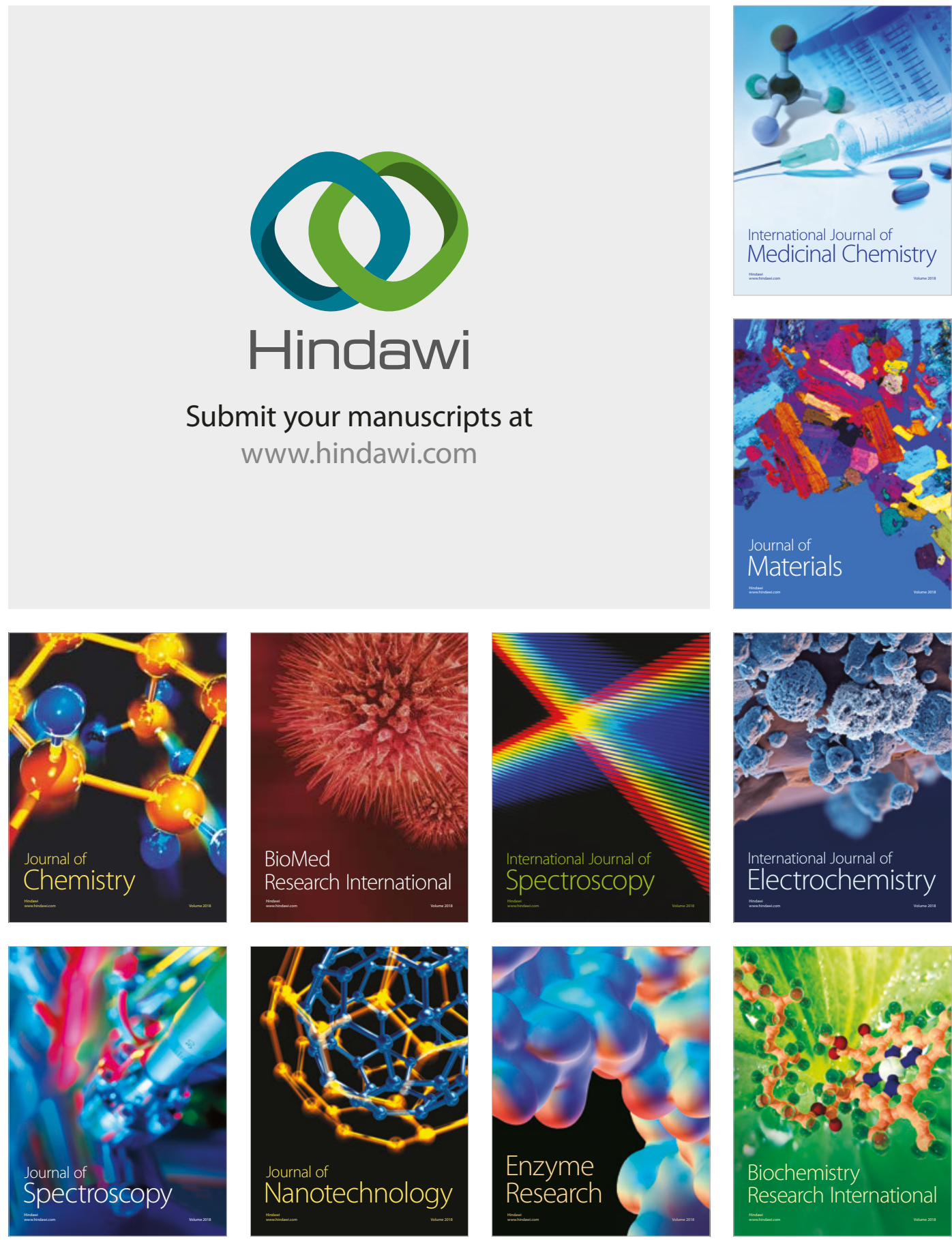
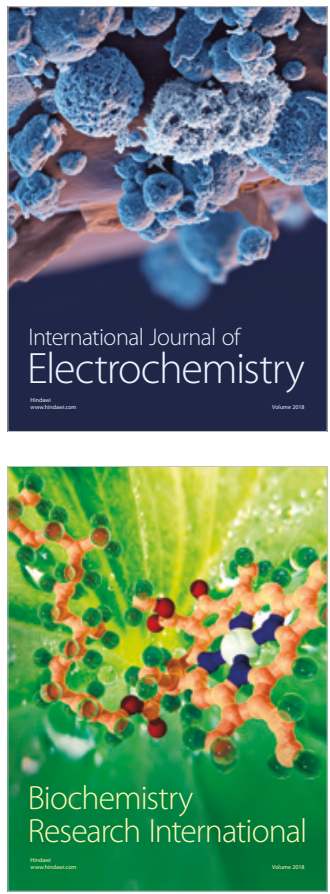